\title{
Risk Behaviors Among Young Mexican American Gang-Associated Females: Sexual Relations, Partying, Substance Use, and Crime
}

\author{
Alice Cepeda \\ Avelardo Valdez \\ University of Houston
}

\begin{abstract}
This research focuses on young Mexican American girls who are not formal gang members yet participate in street-based activities of male gangs and engage in risk behaviors. These females comprise a larger proportion associated with male gangs in inner-city neighborhoods than actual female gang members. Using a qualitative design, the article presents a typology of Mexican American females that reveals a hierarchy based on exposure to four risk-related activities: sexual relations, partying, substance use, and crime. Findings illustrate how outcomes associated with these activities vary according to the girl's relationship to the male gang and status within the community. Also, regardless of their relationship to the gang, participation in these activities resulted in different degrees of negative outcomes. The study concludes that problems associated with these females must go beyond being viewed as individual problems but rather seen within the social, cultural, and economic conditions of their environment.
\end{abstract}

There has been a proliferation of studies on male youth gangs over the past decade but few on how male gangs adversely influence the behavior of other nongang adolescents, especially females (Block \& Block, 1993; Fagan, 1993; Klein \& Maxson, 1987; Moore, 1991). Most studies on females associated with male gangs have focused exclusively on female gang members. These studies have overlooked the largest group of young females associated with gang members who participate in the street-based activities of male gangs and other delinquent lifestyles (Campbell, 1984, 1995; Chesney-Lind, 1993; Miller, 2001, 1998).

This research was supported by the National Institute on Drug Abuse Grant R01 DA08604-03 to the Center for Drug and Social Policy Research, the University of Texas at San Antonio, and the Centers for Disease Control R 49/CCR621048-01 University of Houston.

Journal of Adolescent Research, Vol. 18 No. 1, January 2003 90-106 DOI: $10.1177 / 0743558402238278$

(C) 2003 Sage Publications

90 
The significance of this topic is that it may contribute to an understanding of why, during the past 20 years, females have experienced increases in alcohol and drug abuse, violence, crime, and exposure to HIV/AIDS (Curry, Ball, \& Decker, 1996; Klein, 1995; Miller, 1998; Sanders, 1993). Previous studies emphasize how gender inequality and sexual exploitation shape the risks found within street gang culture that play themselves out in impoverished urban neighborhoods (Lauritsen, Sampson, \& Laub, 1991; Miller 1998). Adolescent females within this context are particularly vulnerable to these risks given their intermediate status between children and adults (Eder, 1995; Lees, 1993).

Using a qualitative design, this article presents a typology of Mexican American females that shows how girls with different degrees of association with the gang behave in four risk-prone social activities: sexual relations, partying, substance use, and crime. In this article, rather than participation in itself, risk behavior will be examined in relation to negative outcomes when engaging in these four activities. Negative outcomes refer to consequences such as pregnancy, violent victimization, sexual assault, and drug abuse. The findings also explore how these behaviors and consequences are related to the young women's status within the larger community and how they negotiate their sexuality and influence gender roles within this social context. A uniqueness of this research is that the participants are much younger (14 to 18 years old) than in previous studies.

\section{Female Adolescent High-Risk Behavior}

The Substance Abuse and Mental Health Services Administration's 1996 nationwide study revealed a steady increase, beginning in 1992, in prevalence rates for use of drugs such as marijuana, heroin, inhalants, and cocaine among females. Similarly, the number of adult women and adolescents arrested and incarcerated is growing faster than that of men (U.S. Department of Justice, 1995). These crimes tend to be nonviolent and nonproperty offenses for adult women and more status related for the adolescent females (Chesney-Lind et al., 1996; Joe \& Chesney-Lind, 1995). However, female adolescent crimes are more likely than those of males to be motivated by interpersonal disputes rather than material gains (Loper \& Cornell, 1995). Female adolescents are also more likely to be victimized by interpersonal and intimate violence such as rape, childhood sexual abuse, and aggravated assault.

Sexual behavior among teenagers has become a public health concern in the United States, particularly because it has higher rates of teenage pregnan- 
cies and birthrates compared to other Western countries (Henshaw, 1997; Kann et al., 1995; Texas Youth Commission, 1996). Furthermore, in recent years, there has been a trend toward lower rates of early initiation to sexual activity and unprotected sex among female adolescents (Ventura, Mathews, \& Curtin, 1998). However, among inner-city African American and Hispanic females, rates have not changed, and these populations continue to engage in unprotected sex at an earlier age, leading to pregnancy and childbearing (Ventura, Curtin, \& Mathews, 1998). Among Hispanics, Mexican American adolescents have the highest birth rate, and U.S.-born Hispanic adolescents have almost double the birth rate of non-U.S.-born Hispanics. In San Antonio, Mexican Americans have one of the highest teenage pregnancy rates in the United States (Schiller, 2000). Early initiation of sexual intercourse, pregnancy, and childbirth are closely related to high school drop out, joblessness, welfare dependency, and increased rates of HIV/AIDS among Mexican Americans and other adolescent females.

\section{Mexican American Female Gang Members}

Gangs can be seen as a representation of a means by which some youths seek to resolve problems presented by their disadvantaged structural position in society and in their community (Campbell, 1995). This situation is even more acute for young females, especially for low-income Mexican American females whose situations are confounded by class, race, and gender issues (Moore, 1991). These problems are exacerbated for those Mexican American females in communities dominated by traditional gender roles (Horowitz, 1983; Valdez \& Halley, 1996; Williams, 1990).

However, little is known about the various ways in which young females are integrated into these male gangs and engage in behaviors associated with substance use, sex, crime, and violent activities (Miller, 1998, 2001). Research generally indicates that female gang members have a higher prevalence of sexual activity and serious criminal involvement than nongang females and males do (Fagan, 1990; Palmer \& Tilley, 1995). The problem with these studies is that they have failed to distinguish how these gangrelated girls vary in their delinquent and risk behaviors.

The study presented here begins to address the gap in the existing literature by focusing on gang-associated females. This study explores how their connection to the gang differentially exposes them to situations often resulting in serious social and health consequences. 


\section{METHOD}

This study combines focus groups and life history interviews to explore and identify the risk behaviors of female adolescents associated with male gangs in San Antonio, Texas. ${ }^{1}$ Data used in this study relied primarily on qualitative responses that were recorded and transcribed. Focus groups and life history respondents were paid $\$ 10$ and $\$ 40$ to $\$ 50$, respectively. Life history/intensive interviews were administered to 160 male gang members, who provided a thorough description of gang activities including their relationship to females associated with gangs.

In addition, data were derived from six focus groups held with females associated with these Mexican American male gang members. Two focus groups consisted of members from two mutually exclusive female gangs; one was comprised of delinquent females, and three others were a mixture of girlfriends, relatives, and friends of male members. A focus group protocol was created that consisted of seven themes: gangs; violence; drug use in relationship to violence; community relationships, thoughts, and dealings with gangs; high-risk sexual behavior; male relationships; and criminal activities. Participants were encouraged to comment and expand on each of the themes. ${ }^{2}$

The source of data for this article also came from ten 1- to 2-hour life history interviews conducted with gang-associated females who were selected based on a preliminary classification developed from life history and focus group data. The preliminary classification consisted of "homegirls," "hoodrats," "girlfriends," and "party girls." Target sampling was used in the selection of the 10 female participants for the life history interviews. This type of sampling ensures that specific types of individuals displaying certain attributes are included in the sample that otherwise may not be included in more traditional random techniques (Berg, 1995). Young girls were selected from each category until a quota of at least two cases in each of the preliminary classification groups was reached. The life history interview focused on family, self, gang, female and male relationships, and sexual behavior.

The first author of this article conducted the 10 interviews. As a young Mexican American female indigenous to the target community, she was able to establish rapport with participants, which was crucial for this study. This rapport was important in that it enhanced the researcher's ability to convey sympathy and understanding without judgment, also eliciting more truthful responses. For instance, females often indicated to the interviewer that they had discussed subjects with her that they had not discussed with anyone else. The interviewer, along with community researchers, was also involved in 
recruitment of the participants for the study. The firsthand involvement gave her a deeper understanding of the social context of the lives of these girls. This level of involvement also contributed to her ability to interpret meanings made by these young females (Rubin \& Rubin, 1995). ${ }^{3}$

\section{Construction and Presentation of Female Typology}

Analysis of this qualitative data was based on the grounded theory approach (Strauss \& Corbin, 1990, 1997). This was accomplished by lineby-line reading of all the qualitative data, identification of key themes, and open and selective coding. The process of typology construction employed logical techniques for the conceptualization of polythetic typologies (Bailey, 1973, 1994), which elaborated the variations in the types of females. Polythetic classes do not contain cases that are identical on all variables but rather group cases by overall greatest similarity (Bailey, 1994). The typology constructed consists of four ideal types: (a) girlfriends, (b) hoodrats (hoodrat was a term that was used by the population to define this group of girls), (c) good girls, and (d) relatives. The typology is clearly not exclusive but fluid, making it possible for girls to move from one type to another in the course of time. Typically, these girls had characteristics of more than one type.

The first type, girlfriend, is characterized as a male gang member's current steady partner. For some of these girls, the girlfriend status is more recent, whereas for others, it has developed into a longer commitment to a partner, often solidified by the birth of a child. Subsequently, included in this type are the young wives who are the mothers of the gang member's children. The motherhood identification gives the young woman a new and higher status and respect as she is no longer referred to as his "girl" but rather as the "mother of his baby." Respect, among other things, means she will be less likely to be sexually and physically harassed by others in the community. Interestingly, this type of female was the least involved in day-to-day gang activities.

The second type, identified as a hoodrat, is a girl that within the community has the most disparaging reputation and is perceived as sexually promiscuous, although this may in fact be a false impression. She is often seen hanging out and partying with the guys and is generally viewed as a heavy polydrug and alcohol user. In fact, many people in the community believe that the gang member's access to illicit drugs is what attracts these girls to the gang in the first place. The hoodrat normally does not develop serious emotional relationships with any of the guys, who often refer to her in derogatory terms. She is not publicly respected by male gang members nor by other girls 
in the neighborhood, and it is difficult to rid herself of her reputation once labeled a hoodrat within the community. Nonetheless, it is this type of female who is most involved in the everyday street activity of the gang. Ironically, involvement in these types of activities, especially crime, does, however, engender a source of respect by some male gang members.

Good girls, the third type in the typology, are the childhood friends of many male gang members. For many of these girls, these friendships were developed in the same neighborhoods where they grew up. These girls attended the same schools and were usually in the same grade level as their male counterparts. In some instances, their parents and/or other relatives interacted with each other. Through the course of time, these childhood friendships developed into relationships based on mutual respect. Most males refer to these girls as "nice girls." Most of the good girls follow more traditional gender roles and values compared to other girls. They are perceived as less streetwise and less likely to be involved in illegal drug use or criminal activities. They live what Moore (1994) identified as a conventional lifestyle in her study of Mexican American female heroin users.

The final type, relatives, consists of girls who are close kin to gang members, for example, sisters and cousins. Their identification as relatives affords the young women a special status within the network. For instance, if one of these young women has a boyfriend in a gang, she is not only seen as his girlfriend but, more important, as a homeboy's sister or cousin. Both the girlfriends and relatives had limited involvement in the male gang member's activities.

\section{Themes}

This typology allowed us to explore the extent to which these females are exposed to high-risk behavior based on five key themes. The themes were developed by focusing on the behaviors of the females within the context of the male gang activities. The activities that proved to be most salient in understanding these women's roles in the context of the male gang were sexual relationships, partying, substance use, and crime. Although all the girls were associated with male gangs, the extent of their participation and exposure to these four activities was found to be related to negative outcomes.

\section{Sexual Relationships}

As found in other studies (Erickson, 1998; Horowitz, 1983), adolescent females in this study had an early age onset of sexual intercourse, compared to national rates (Braverman \& Strasburger, 1993). In discussions with the 
young females associated with the gang members, most admitted to having a sexual experience by their early teens; many had become pregnant, and approximately one-fourth had given birth.

Girls in this gang subculture are socially categorized by how they relate sexually to the gang members. Many of the male gang members seem to be involved sexually with two distinct types of girls: girls with whom they have significant steady relationships and girls with whom they have casual sexual relationships. The significant relationships are usually with the girlfriend/ mother type. Most of the male gang members reported to be presently involved in an emotional relationship with a girlfriend that often developed into live-in relationships. For example, CJ is a member of one of the most notorious gangs in San Antonio. CJ's common-law partner stated, "We've been together for 5 years, and we've been living together for 2 years. We have a little girl, Amber; she's going to be 2." CJ described the mother of his child as a "nice girl who is pretty smart."

In contrast, casual relationships tended to be with the hoodrat types. For the most part, the relationships the males had with these hoodrats were based primarily on sex and an absence of any emotional connection. Biggy, a wellknown San Antonio gang member, described the difference between his girlfriend and a hoodrat in the following account:

A respectable girl is like if I had a chick. I liked her a lot and everything. She will be my main chick, and all my boys respect her. Other chicks or whatever, they're just hoodrats and bitches. She's like my bitch, so I don't give a damn about her. I just do whatever I want with them. Sometimes I'll be with them [hoodrats] and my homeboy comes over. He could start hugging her or kissing her or whatever. That's a hoodrat.

Although the community perceives hoodrats as being "loose" (sexually available), these girls have some very different opinions about their roles. One 17-year-old girl, who is perceived to be a hoodrat, described her reasons for not having a boyfriend:

I don't want a boyfriend because I don't want some guy telling me what to do. And the girls, well I don't like hanging around them because they are all backstabbing bitches. They see me in my little dresses all dressed up and they just think I am out to steal their guys. They're stupid. I am not even looking at the guys. These girls start yelling at me and start calling me a "ho."

Although this girl self-identified herself in the interview as a hoodrat, she did not accept the pejorative connotation associated with the label. 
The other two types, although generally identified as good girls and relatives, may in time transition into a girlfriend status. For example, good girls can eventually become girlfriends and receive dual respect from the males in the gang. A relative can also become a girlfriend if a relationship is developed with a male gang member. Usually, the role change from relative to girlfriend occurs among a gang member's sisters and other relatives. It is common among friends for one of them to have a relationship with a sister or other close relative. This is especially the case when friends frequent the residences of homeboys who have younger sisters. For instance, the following field note describes a young girl's transition from her status as a relative to girlfriend within the gang:

Missy is 16 years old and has a brother in TK. Her brother and his friends used to hang out in front of her home. The guys used to come over and smoke weed and drink outside at all times. This is how she met Joey (current boyfriend), her brother's best friend, who, according to Missy, was very popular with all the girls.

Similarly, during a focus group, a young female described her relationship with her boyfriend: "I grew up with all of the MBT. He was a good friend before he became my boyfriend." Conversely, some of these young females can be labeled as hoodrats depending on how they relate to the males sexually. That is, if they are seen as engaging in unbounded sex, they may be identified as hoodrats. Girls in this community are constantly negotiating their image within these social boundaries of the good girl image. The guys, on the other hand, may have sexual relationships with multiple girls and not be sexually labeled. This sexual double standard often forces these young women into further isolation and community stigmatization.

Considering the fact that the majority of the young women in this study were sexually active, contraceptive use was commonly discussed. The girlfriends/wives reported not using condoms with their partners. Many believed that because they were the only partners with whom the males were sexually active, condom use was not necessary. Some reported, as in other studies among similar populations, that if they were to ask their partners to use a condom, the partner would think she was having sex with others. The remaining types (good girls, relatives, and hoodrats) reported more frequent use of condoms, although it was not a consistent practice. When condoms are used, it is for protection against sexually transmitted diseases rather than to avoid pregnancy.

These descriptions indicate how a girl's relationship to the male gang and its members influences her exposure to high-risk sexual behavior. The girl- 
friends, good girls, and relatives tend to have more stable and significant sexual relationships with male gang members, characterized as continual, long term, and affectionate. In contrast, the hoodrat is more likely to have multiple sexual relations with various male members.

\section{Partying}

Partying is an activity that seems to expose girls to different levels of risk. Partying was described as a social gathering that usually occurs in locations such as residences, public parks, and isolated streets and alleyways. The respondents discussed two categories of partying. In both kinds of parties, alcohol (usually beer), marijuana, and cocaine are consumed by most of the attendees. The first party category consists of social gatherings that occur spontaneously and are often restricted to male gang members. There is usually heavy alcohol and polydrug use at these types of parties, and the primary objective, according to several respondents, is to get "loaded and high." The second category of partying is described as a more conventional gathering, which includes birthday parties, barbecues, and family-oriented events.

Girls who attend the spontaneous parties are usually the hoodrats. They attend these parties because of the availability of free drugs and alcohol and because they like to get high and hang with the guys. One male member described the girls who came to parties as follows:

They just like being around the boys, around everybody. They just party with us, they're just everywhere we go, do whatever we do. They want to be there hanging around with us. Fuck it, we're partying and they party with us.

One girl described a party she had recently attended: "I went to this last party. They had a keg. They also had a piñata with condoms, birth control, weed, everything! It was a good party. There were a lot of guys." Conspicuously absent from these parties are the other types of females, especially girlfriends.

Girls at these parties may give the impression that they are sexually available, but this is not always the case. Most of the girls can control themselves and avoid getting "so wasted they don't know what they're doing." This controlled behavior is important in avoiding any forced sexual contact or other form of violence by some males who will take advantage of them if given the opportunity. This is not to say that these young women will not have sex with these males, but it is usually their own decision to do so. However, these parties are potentially dangerous for girls less experienced or disconnected from 
others who will protect them. One female described how a girl whom none of the other young women knew was raped at one of the gang's parties:

She was already drunk when she came to the party. I think she was 17 , but I'm not too sure. She was a new girl. She didn't know nothing about the Brothers (male gang). She didn't know nothing at all, nothing about gangs, drugs. All she knew about was drinking and drinking and drinking, and that's it.

The Brother, he just took her to a bedroom. He was telling her that he wanted to show her something. She went up to the room after he told her that he had a diamond ring for her. So she went upstairs. He put alcohol on some rag and covered her face. That's all I heard. My homeboy said just go home, and I went. He told me that he didn't want nothing to happen to me, and I just went home.

This illustrates one of the more high-risk situations some of the young women find themselves in when attending these spontaneous parties. Such social environments, given the excessive use of alcohol and drugs, increase the girl's risk of violent, physical, and sexual victimization.

Those girls incorporated into the second category of more conventional parties include the girlfriends/wives, good girls, and relatives. On these occasions, the scene is composed exclusively of these types of females, young children, and other relatives. Excessive drinking and drug use and boisterous behavior are absent from these social gatherings. In describing these parties, one male gang member stated, "They are for the weekends when everybody gets together to kick it. That's the only time I ever see them with my camaradas [close friends]." Most male gang members emphasized that these parties were only for trusted friends and their girlfriends and family. Mark, a member of the Knights, was with his girlfriend for a full year before he took her to one of these parties. He said, "I only took her once. That's it." The fact that Mark took a year before he invited his girlfriend illustrates the special nature of these social gatherings and their exclusiveness. The time spent with girlfriends at these gatherings, therefore, is seen by the gang members (and the girls) as a refuge and shelter from the intense lifestyle (i.e., violence and substance use) associated with their lives.

Similar to the girlfriends, the good girls and the relatives had limited participation in the spontaneous parties. Most either preferred not to hang out with the young men on partying occasions or were not allowed to. In particular, the relatives tended to be protected from such parties by older brothers or cousins. These relatives were kept away from the party scene because of the excessive drinking and drug use that typically occurred. The only occasions 
in which these two types of young women were included were during the more conventional parties that the girlfriends attended.

\section{Substance Use}

Another risk-related activity associated with these females was their alcohol and drug use. However, there were distinct patterns of use among and within the different types of females in our study. For instance, girlfriends reported a pattern that ranged from nonuse to occasional. Nonuse tended to be most common among those who had just recently become emotionally attached to a male. Because male members prefer to exclude these new girls from their gang's activities at the initiation of their relationship, contact with members of the male gang and exposure to illicit drug use is minimal. Sonic, a member of the Thugs, described his current girlfriend in these terms: "She's a nice girl and a very smart and high-class girl. She lives outside the neighborhood. She doesn't do any drugs."

However, there were those girlfriends who reported occasional drug use, in particular, marijuana and cocaine. These females tend to be those who are involved in a more serious long-term relationship. Although this type of girlfriend has limited participation in her partner's gang activities, the long time exposure to her boyfriend's lifestyle puts her at higher risk for drug use. These young women often speak of being encouraged to use drugs (usually marijuana) when they are alone with their boyfriends.

The hoodrats are more frequent users of alcohol and drugs than the other females are. Polydrug use and alcohol is a common everyday experience for this type of girl. One girl stated,

I know some guys who will hook us up for free. I like doing drugs. I have done both pot and cocaine and a little bit of heroin. I tried shooting up about three times but I really did not like it.

The repercussions of this drug use behavior among these types of girls may sometimes lead to sexual exploitation and violence. One respondent described how she saw a 17-year-old girl from the neighborhood get "gang raped" after a party:

Everyone had been drinking and smoking [weed]. She always wanted to be around the guys. After almost everyone had left, three members of the TMA took her into the back room and "pulled a train" on her. She was all fucked up. She wanted to do it because she did not fight back. Everyone in the neighborhood knows this happened but she still hangs out with them like nothing. 
Apparently, this young girl had no ties (i.e., brother, boyfriend, etc.) with any of the members of the TMA. This may have influenced the perpetrator's behavior, knowing there would be limited, if any, consequences.

Good girls' and relatives' exposure to drug and alcohol use was limited due in large part to being denied access to these substances by male members. However, these young women were occasional users of alcohol and marijuana that they typically would obtain from good friends of the male gang or older siblings and/or cousins. Drug use among these types of girls did not lead to problem behaviors such as high-risk sexual encounters or physical violence.

\section{Crime}

Involvement in criminal or violent activities varied among the types of girls identified in this study. Hoodrats were more likely to participate in illegal activities in association with male gang members. These females are used to hiding and stashing either weapons or drugs for gang members in locations less vulnerable to police. A member of the Knights stated, "If the cops are after us, we make them [girls] hold the guns. Everyone knows the police are not going to search the women."

Another criminal activity that frequently involves hoodrats is using them to lure rival male gang members to locations where they could be assaulted, undetected by authorities. Under the illusion that the female is interested in him, the rival member is taken to a designated place where he is physically attacked. A 14-year-old female adolescent described how the male gang members (BBG) asked her to help them:

He was from the Eastside. They couldn't stand him. He wouldn't go into the courts [public housing]. They hated him because he would talk shit. And then they told me, "Tell him to walk you home." I was like "Hell no!" Then they told me, "Come on we'll give you 10 bucks." I said all right. I told him, "Hey could you walk me home?" He said, "You live in the courts?" Yeah. "All right I'll walk you through the park." Okay go for it. I took him around and made him walk me through the middle of the park. They kicked his ass. I was laughing.

Some hoodrats were involved in more serious activities such as drug dealing and weapon sales. These activities, however, were often done independently from those of the male gang. Similar to males, these females strive to gain economic independence by engaging in such illegal activities. Nonetheless, some females took advantage of opportunities offered by the male gangs to participate in criminal activities. For example, females discussed how they had been involved in "popping a car" (car jacking). 
The girlfriends', good girls', and relatives' participation in such illegal activities was nearly absent. There was not much evidence of their being involved in any illegal activity, although there were some relatives who reported having been involved in "holding drugs" for their homeboys. One girl revealed that she was selling for her older brother: "I sell for my brother sometimes. He leaves then he comes back and he will fall asleep. He lets me sell. People will come and shit, I just sell!"

These data suggest that female criminal involvement is restricted to the hoodrat and on occasion some of the other types of girls. The hoodrats see their involvement in gang-related criminal activity as yet another gesture of being welcomed into the male gang. Male gang members involve the girlfriends or relatives in less serious and less aggressive crimes.

\section{DISCUSSION}

This study has demonstrated how females associated with male gang members and their activities increase their likelihood of engaging in activities that have negative personal and social consequences. This study found that regardless of their relationship to the gang, all the females were prone to some degree of substance use, crime, and high-risk sexual behavior. Although the hoodrats were clearly the most at risk due to the nature of their involvement in gang activities. This finding parallels social network studies that associate risk behavior and negative consequences with the individual's immediate social relationships and level of relationship, rather than focusing only on the individual's attributes (Friedman et al., 1999). The association of high-risk behavior with increased involvement in gang activities is also supportive of the social facilitation model discussed by Thornberry, Krohn, Lizotte, and Chard-Wierschem (1995) that focuses on delinquency careers.

Our analysis reveals that behaviors associated with sexual relations emerge as having the most negative outcomes among these young females. The girlfriends, good girls, and relatives, although sexually bound to a steady partner, were still exposed to sexually transmitted diseases and infections associated through their partner's multiple sexual relationships and high-risk drug use, such as injecting heroin. In addition, a girl involved in a close relationship compared to one who is not may be more likely to have unprotected sex, become pregnant, and experience full-term pregnancy, in contrast to those who do not have an intimate partner and choose to not have the child.

The hoodrats, on the other hand, may be open about their sexuality and more likely to have casual, multiple, and serial sexual partners. As well, these women may be openly involved in gang street activities such as violence 
offending, criminality, and substance and alcohol use. This makes them vulnerable to sexual and violent victimization, court involvement, drug dependency, and other negative social and health consequences. The social cost of this behavior results in being stigmatized and marginalized by the other types of young females, male gang members, and the community. This type of sexual behavior by all these girls may explain the comparatively high rates of new cases of HIV/AIDS among young Hispanic women (Centers for Disease Control, 1999).

One of the intriguing findings from this study is how traditional gender roles associated with Mexican American culture are being influenced by the behavior of these females. The girlfriends accept and portray the images and roles of passivity and submissiveness associated with traditional gender roles (Williams, 1990). Good girls and relatives subtly challenge these gender roles by renegotiating their sexuality while rejecting passivity and submissiveness similar to what has been described by Horowitz (1983). The hoodrats, on the other hand, openly challenge these more traditional gender roles by their unbounded sexual behavior and independence (Horowitz, 1983; Williams, 1990). For these young women, the exciting nature of the gang and streets may seem more appealing to them than do traditional gender behaviors. In the process, these girls' behavior may be creating a new social identity for women that goes beyond the traditional good girl/bad girl associated with Mexican American gender roles.

Young female adolescents are expected to adhere to a moral prescription for timing of sex, marriage, childbearing, and avoidance of criminal and other delinquent behavior. Middle-class-based norms also demand certain levels of education that in turn delay the appropriate age for reproduction events into the 20 s and early 30 s. Other value-laden sense norms expect adolescents and even adults to not use illicit drugs or consume excessive amounts of alcohol. Clearly, the females described in this study, as do many other lower-class females, do not follow this middle-class American script (Erickson, 1998; Jencks, 1990).

What may explain this behavior among Mexican American females is that they seem to have an alternative normative course. These findings suggest that early sexual activity, reproduction strategies, and excessive use of drugs and alcohol may be recognized as normative within this population given their perceived limited opportunities. Moreover, the street culture and lifestyle of these gangs creates a symbiotic relationship with these male gang members that encourages a withdrawal from societal norms. This creates a social environment in which risk behaviors as described in this study are modeled, practiced, and reinforced similar to Moore's (1991) concept of "choloization." In this sense, problems associated with these females must go 
beyond being viewed as an individual problem but rather seen within the social, cultural, and economic conditions of their environments.

Similar findings have been suggested for African American young females (Burton, 1990; Franklin, 1988) who engage in similar behaviors to those of Mexican Americans. Indeed, choices made by these gang-associated females may be the "rational choice" in the face of the limited options and opportunities available to them. As with other qualitative studies, the generalizability and interpretability of these data are somewhat limited until comparable investigations are done with similar populations. Future research should develop specialized prevention and intervention strategies aimed at reducing the risk of violence and high-risk sexual and drug abuse behavior practices among adolescents within these kinds of social backgrounds.

\section{NOTES}

1. Persons of Mexican origin comprise approximately $56 \%$ of the total population. San Antonio has a per capita poverty rate of $23 \%$. However, poverty in San Antonio is disproportionately a Mexican-origin phenomenon with 28\% of Mexican Americans living below the poverty level.

2. See Valdez and Kaplan (1999).

3. Further evidence of the researcher's rapport with the participants was that many continued to maintain contact with her throughout the length of the study. Usually this contact was a friendly follow-up call and at other times calls were related to specific problems, requests, or referrals (i.e., employment, medical, social services). This allowed the research team to obtain collateral information about the validity of the life history and focus group data.

\section{REFERENCES}

Bailey, K. D. (1973). Monothetic and polythetic typologies and their relation to conceptualization measurement and scaling. American Sociological Review, 38, 18-33.

Bailey, K. D. (1994). Typologies and taxonomies: An introduction to classification techniques. Thousand Oaks, CA: Sage.

Berg, B. L. (1995). Qualitative research methods for the social sciences. Needham Heights, MA: Allyn \& Bacon.

Block, R., \& Block, R. (1993). Street gang crime in Chicago (research in brief). Washington, DC: U.S. Department of Justice, Office of Justice Programs, National Institute of Justice.

Braverman, P. K., \& Strasburger, V. C. (1993). Adolescent sexual activity. Clinical Pediatrics, $32,658-668$.

Burton, L. M. (1990). Teenage childbearing as an alternative life course strategy in multigenerational Black families. Human Nature, 1, 123-143.

Campbell, A. (1984). Girls' talk-The social representation of aggression by female gang members. Criminal Justice and Behavior, 11, 139-156. 
Campbell, A. (1995). Female participation in gangs. In M. W. Kline, C. L. Maxson, \& J. Miller (Eds.), The modern gang reader. Los Angeles, CA: Roxbury.

Centers for Disease Control. (1999). HIV/AIDS among U.S. women: Minority and young women at continuing risk (Fact sheet). Atlanta, GA: Division of HIV/AIDS Prevention.

Chesney-Lind, M. (1993). Girls, gangs and violence: Reinventing the liberated female crook. Humanity and Society, 17, 321-344.

Chesney-Lind, M., Shelden, R. G., \& Joe, K. A. (1996). Girls, delinquency, and gang membership. In C. R. Huff (Ed.), Gangs in America (2nd. ed., pp. 185-298). London: Sage.

Curry, G. D., Ball, R. A., \& Decker, S. H. (1996). Estimating the national scope of gang crime from law enforcement data (Research in brief). Washington, DC: National Institute of Justice.

Eder, D. (1995). School talk: Gender and adolescent culture. New Brunswick, NJ: Rutgers University Press.

Erickson, P. I. (1998). Latina adolescent childbearing in East Los Angeles. Austin: University of Texas Press.

Fagan, J. (1990). Social processes of delinquency and drug use among urban gangs. In C. R. Huff (Ed.), Gangs in America (pp. 183-219). Newbury Park, CA: Sage.

Fagan, J. (1993). The political economy of drug dealing among urban gangs. In R. Davis, A. Lurigio, \& D. P. Rosenbaum (Eds.), Drugs and community. Springfield, IL: Charles C Thomas.

Franklin, D. L. (1988). Race, class and adolescent pregnancy: An ecological analysis. American Journal of Orthopsychiatry, 58, 339-354.

Friedman, S. R., Curtis, R., Neaigus, A., Jose, B., \& Jarlais, D. C. D. (1999). Social networks, drug injectors' lives, and HIV/AIDS. New York: Kluwer Academic.

Henshaw, S. K. (1997). Teenage abortion and pregnancy statistics by state, 1992. Family Planning Perspectives, 29, 115-122.

Horowitz, R. (1983). Honor and the American dream: Culture and identity in a Chicano community. New Brunswick, NJ: Rutgers University Press.

Jencks, C. (1990). Is the American underclass growing? In J. Jencks \& P. E. Petersen (Eds.), The urban underclass (pp. 28-100). Washington, DC: Brookings Institute.

Joe, K. A., \& Chesney-Lind, M. (1995). Just every mother's angel: An analysis of gender and ethnic variations in youth gang membership. Gender \& Society, 9, 408-431.

Kann, L., Warren, C. W., Harris, W. A., Collins, J. L., Douglas, K. A., Collins, M. E., et al. (1995). Youth risk behavior surveillance-United States, 1993. Morbidity and Mortality Weekly Report, 44(SS-1).

Klein, M. W. (1995). The American street gang: Its nature, prevalence, and control. New York: Oxford University Press.

Klein, M. W., \& Maxson, C. L. (1987). Street gang violence. In M. Wolfgang \& N. Wiener (Eds.), Violent crime, violent criminals. Beverly Hills, CA: Sage.

Lauritsen, J. L., Sampson, R. J., \& Laub, J. H. (1991). The link between offending and victimization among adolescents. Criminology, 29, 265-292.

Lees, S. (1993). Sugar and spice: Sexuality and adolescent girls. New York: Penguin.

Loper, A. B., \& Cornell, D. G. (1995, October). Homicide by girls. Paper presented at the annual meeting of the National Girls Caucus, Orlando, FL.

Miller, J. (1998). Gender and victimization risk among young women in gangs. Journal of Research in Crime and Delinquency, 35, 429-453.

Miller, J. (2001). One of the guys. New York: Oxford University Press. 
Moore, J. W. (1991). Going down to the barrio: Homeboys and homegirls in change. Philadelphia: Temple University Press.

Moore, J. W. (1994). The chola life course: Chicana heroin users and the barrio gang. International Journal of the Addictions, 29, 1115-1126.

Palmer, C. T., \& Tilley, C. F. (1995). Sexual access to females as a motivation for joining gangs: An evolutionary approach. Journal of Sex Research, 32(3), 213-217.

Rubin, H. J., \& Rubin, I. S. (1995). Qualitative interviewing: The art of hearing data. Thousand Oaks, CA: Sage.

Sanders, W. (1993). Drive-bys and gang bangs: Gangs and grounded culture. Chicago: Aldine.

Schiller, D. (2000, December 23). Bexar teen birth rate above norm. San Antonio Express News.

Strauss, A., \& Corbin, J. (1990). Basics of qualitative research. Newbury Park, CA: Sage.

Strauss, A., \& Corbin, J. (1997). Grounded theory in practice. Thousand Oaks, CA: Sage.

Texas Youth Commission. (1996). A summary of Child Health And Safety Initiative. Austin: Texas Department of Health, Office of Prevention, Texas Youth Commission.

Thornberry, T. B., Krohn, M. D., Lizotte, A. J., \& Chard-Wierschem, D. (1995). The role of juvenile gangs in facilitating delinquent behavior. In M. W. Klein, C. L. Maxson, \& J. Miller (Eds.), The modern gang reader. Los Angeles: Roxbury.

U.S. Department of Justice. (1995) Crime in America. Uniform Crime Reports, FBI 213.

Valdez, A., \& Halley, J. A. (1996). Gender in the culture of Mexican American conjunto music. Gender \& Society, 10, 148-167.

Valdez, A., \& Kaplan, C. D. (1999). Reducing selection bias in the use of focus groups to investigate hidden populations: The case of Mexican American gang members from south Texas. Drugs and Society, 14, 209-224.

Ventura, S. J., Curtin, S. C., \& Mathews, T. J. (1998). Teenage births in the U.S.: National and state trends, 1990-1996 (National Vital Statistics System). Hyatsville, MD: National Center for Health Statistics.

Ventura, S. J., Mathews, T. J., \& Curtin, S. C. (1998). Teenage births in the United States: State trends, 1991-1996. An update. Monthly Vital Statistics Report, 46(11, Suppl. 2). Hyatsville, MD: National Center for Health Statistics.

Williams, N. (1990). The Mexican American family: Tradition and change. Dix Hills, NY: General Hall.

Alice Cepeda is a Ph.D. student in the sociology program at the City University of New York Graduate Center. She is also a senior researcher at the University of Houston, Graduate School of Social Work, Office for Drug and Social Policy Research. Currently, she is working on her dissertation focused on sex workers along the U.S.-Mexico border.

Avelardo Valdez is a professor at the University of Houston, Graduate School of Social Work and director of the Office for Drug and Social Policy Research. His current research and publications focus on drugs, violence, adolescent gangs, and sex workers in south Texas and the U.S.-Mexico border. 